Andrew Stables*

\title{
Perceived Ontological Levels and Language Games
}

\section{The problem of analysis as a scholarly and educational ideal}

\begin{abstract}
This paper argues against assuming that analysis, in the sense of breaking things into their constituent parts, can result in understanding of either universal truths or unequivocal local realities. "Analysis” most commonly refers to the process of looking into things to identify their constituent parts and the relations between them. To Kant, an analytic fact is self-evident. However, a phenomenon is only recognized as such at particular ontological, or perceptual, levels; when approached as a series of sub-phenomena, the question to which we are responding is not "what is this made of," so much as "what are you reminded of when you look into this?" Therefore, analysis is a process of semiotic interpretation rather than pure logic: the response to a series of prompts in a particular context, where those responses are individual variations on sociocultural habits of response. Analysis is therefore analogical and intersubjective, and this should be recognized within educational and scholarly practices. On this account, ontological levels are better understood as perceptual levels. Analysis should therefore be preceded by explanatory sensitivity, as construals of any entity are dependent on the contexts that locate that entity. Some practical examples and implications for education are offered.
\end{abstract}

Keywords: construals; perceptual levels; scholarly practices; semiotic interpretation

*Corresponding author, Andrew Stables: University of Roehampton, London, UK, email: andrew.stables@roehampton.ac.uk

\section{Introduction: Beyond naïve scientific realism}

All objects of human perception are validated with reference to human experience in one form or another. Nothing is interpretation free. This is true both of how things are perceived as wholes and in terms of their constitutions. The emphasis in this paper is on interpretation of constituent parts, but it is 
pertinent to note that sometimes agreement over constituent parts nevertheless results in different interpretations of the whole. Wittgenstein's duck-rabbit is perhaps the best-known example of this in the philosophical literature: a simple line drawing that can be interpreted as representing one of two distinct entities depending on which pattern recognition has dominance with the observer. Note that while there is a subjective element to this, the choice is not arbitrary, as all observers are likely to recognize the pattern as duck or rabbit: only two strong possibilities are available within the observing culture (Wittgenstein 1967, Part 2: xi). Sometimes, as in the case of the Rorschach inkblot test (Rorschach 1927), interpretations can be various and are taken to manifest psychological aspects of the observer.

A recent social media phenomenon was the case of the blue-black or goldwhite dress in 2015. Here, physicists could explain the conditions under which an observer would see the dress as a particular color combination. This therefore might be seen as a variation on the duck-rabbit, as the candidate responses can superficially be explained as physical rather than cultural but this might be construed as misleading given that the assignations of the responses as individual colors again manifest choices from a culturally determined pallet. Were this not the case, the responses might not have seemed polarized into an either-or choice, and individuals' responses could simply be mapped onto a continuum, albeit the terms defining the polarities would still be matters of cultural choice. ${ }^{1}$

It might be argued that while this shows how the assumption of understanding through identifying constituent parts can mislead, it is an exception that proves the rule. After all, the vast majority of the time, we do not apparently experience dissensus over what we are seeing. However, this only holds true at the level of simple object recognition. If we have been taught what a box is, we tend to recognize a box as a box, as it were. Of course, the same level of recognition does not extend to the consideration of significance. There will always be greater differences when it comes to responding to an object in terms of its significance for an observer, but such differences are often ironed out in the shorthand of functional communications.

Given that cultural perspectives are contingent, albeit the result of slow changes that are not always apparent at the conscious level, it can be argued that all analysis is contingent.

1 See: http://www.theguardian.com/.../science-thedress-colour-illusion-the-dress-blue-blackgold-white, accessed January 16, 2016. 
Consider physical and biochemical analysis at the molecular level and below. Substance metaphysics has favored explanations in terms of monadic particles in mutual relation, though process accounts might focus on waves or bursts of energy, with string theory offering a potential marrying of these traditions. Behind each of these orientations is a tradition. For example, substance accounts can be traced from Aristotle's search for the primordial unmoved mover through the Newtonian model of a universe comprising material entities exercising force on each other. The process tradition can be traced from Heraclitus' writings on flux through Faraday to Whitehead and beyond (Whitehead 1929). The fact that these traditions are assumed rather than problematized in the day-to-day work of scientists does not render them noncontingent.

With its emphasis on contingency, the present argument can be seen as relativist. However, it is not anti-realist. (It is a common fallacy that relativism is the opposite of realism.) Returning to the case of the two-tone dress above, it is evident that scientists can explain how context (broadly understood) determines how the eye perceives color. This does not deny the reality of these physical and chemical operations but it does challenge the assumption that color is an inherent quality. It takes a certain concatenation of circumstances to see a color as a color. Color may not be commonly regarded as divisible in the sense that a red thing comprises many small red things while there may be a stronger tendency to regard, say, bread as comprising bits of bread. "Trace of color" has different ontological salience from "slice of bread." However, each is culturally contingent. Just as the boundaries of redness are open to question, so are those of bread. Indian breads do not look much like Western breads, for example.

There is no innocent direct view of noumenal reality. When we say we have seen something, we assume we have seen it. For example, for some time scientists have studied atomic activity. However, it is only recently that scientists have claimed to be able to see atoms directly, while seeing molecular bonds has proved even more problematic, whereas subatomic particles (photons, neutrons, electrons) can only be observed indirectly, from their traces or "tracks." 2

2 See the following websites:

http://motherboard.vice.com/read/this-microscope-can-see-down-to-individual-atoms; http://singularityhub.com/2009/09/01/microscope-sees-molecules-for-first-time/; and https://www.researchgate.net/post/Is_it_possible_to_view_any_sub-atomic_particles_ like_electron_proton_or_neutron. 
The continual refinement of atomic theories has not proceeded without data, but the identities of those data have been inferred or implied. The hypotheses are not, as Popper suggested, attempts to refute but rather, usually, to confirm. On these grounds, physical scientists are arguably guilty of the same weakness as social scientists who "read" society as evidence for a theoretical position (such as Marxism or capitalism) and only revise the theory when the data stubbornly refuse to repeatedly enact the theory. This is very different from seeking refutation in every hypothesis.

Atomic structures, therefore, can only be taken as givens within a particular, albeit powerful, language game: that of theoretical physics, the twentieth century's version of natural philosophy. At a purely perceptual level, all these images reveal are lumps of light in patterns of greater or lesser regularity. Experts in this particular language game (which is at heart a mathematical as much as strictly a language game, but a semiotic system nevertheless), recognize similarities and differences between these images that allow them to make connections, including many that the general public finds hugely informative and helpful, such as around repetition of DNA sequences. However, even DNA strands cannot be clearly seen under a microscope. ${ }^{3}$

What happens in DNA analysis is that the overall picture of a DNA sample is compared with others. That is, the recognition of constituent parts comes after the direct, under microscope, recognition of pattern, so the whole can only be assumed to be constructed from the parts. The "parts" meanwhile are derived from theory. ${ }^{4}$

All recognition stems from, and most operates at, what might be termed the human quotidian perceptual level (QPL: the level on which we recognize a pizza as a pizza). Scientific analysis, via microscope, telescope, and other means that claim to show what cannot be directly perceived, operates at an inferred constructional level (ICL). Note that the latter is inferred from explanations that derive ultimately from QPL. Any conception of that which is assumed to exist at the atomic level, for example, can only be drawn from experience in the broadest sense (that is, not merely direct sensory input as per classical empiricism).

Many such conceptions are immediately modeled by existing conceptions in the explanatory field in question. However, there remains no other possible prior source than QPL. All accounts must make sense at QPL whatever their derivation. Indeed, the test of theories at ICL is that they ring true at QPL. The

3 See: http://www.nytimes.com/2008/06/03/science/03qna.html?_r=0? 4 See: http://biotechlearn.org.nz/focus_stories/forensics/dna_profiling. 
telescope and microscope have somewhat expanded QPL but, as the above examples affirm, remain not the source of insights at ICL. Rather, assumptions at ICL wait for empirical evidence to either confirm or deny them.

\section{Ontological/ perceptual levels}

At first blush, it might seem that the present argument can be countered by the simple recognition that the scientific community accepts that there are ontological levels. Furthermore, sometimes qualities at higher levels supervene on those at lower and sometimes not (e.g. Hartmann 1935). If scientists were to study a pizza at the atomic level, they would not expect to find tiny bits of pizza, but rather atomic structures; therefore, the present argument against the claims of analysis involves a straw man.

However, what actually misleads here is the concept of ontological level, for it can imply, if taken at the level of naïve scientific realism, that the atoms are as much "simply there" as is the pizza. The present argument is that both the attribution of pizzahood and that of atom structure are derived from specific traditions and worldviews; neither is "simply there" but is an object of (often unquestioned) interpretation. Thus, the ontological layers are rather perceptual layers: when we make the first incisions, we perceive pizza slices; when we employ the electron microscope, we perceive, perhaps with somewhat less clarity, atomic and molecular behavior. The present argument rejects fundamentalism, while discussion of ontological levels tends to assume levels of foundationalism, or at least fail to dispel such assumptions.

Again, many scientists of a pragmatist disposition might argue that there is no new substantive argument here, as they acknowledge that both our naming of real-world objects and the development of our scientific explanations are constrained by culture and tradition, as well as by the limits to interpretation that nature affords, and that this may not invalidate the quest for foundations, since certain explanations are effectively allowed to work better than others. The present argument goes one step beyond this, however, in claiming that explanations at the ICL can only be derived from the already culturally interpreted world of the QPL. Thus, studies that claim to be unlocking the mysteries of the universe are always dependent on routine assumptions of daily life. This raises the possibility that the everyday surface world remains our strongest source of progressive understanding. It follows that instead of simply pursuing the apparently cumulative agenda of refining subatomic theory, more resource should be put into studies in the culture and philosophy of science that 
consider more carefully, as Gooding did with Faraday (see below), how these explanations are derived. To effect such a shift would, of course, involve confronting the complaint that scientific progress was being slowed.

However, the case can be made that scientific progress has in fact been slowing for some time, with an ever-increasing emphasis on the incremental at the expense of the exploratory and groundbreaking. This is not, of course, a case that can be proven in any strong sense, not least because researchers can always claim that they are on the verge of major breakthroughs. It is, however, a position that has been argued by significant voices within the science and scientific journalism communities. According to Michael Hanlon (2016):

That true age of innovation - I'll call it the Golden Quarter - ran from approximately 1945 to 1971. Just about everything that defines the modern world either came about, or had its seeds sown, during this time. The Pill. Electronics. Computers and the birth of the internet. Nuclear power. Television. Antibiotics. Space travel. Civil rights. There is more.

While Hanlon hedges his bets here ("either came about, or had its seeds sown") and is also simultaneously specific and unfocused in his examples of what "defines the modern world," there is at least a present danger, if not an active case, that systems of both scientific funding and educational curricula that are strongly focused on apparently achievable incremental outcomes, and which deny the value of basic research, critical revisionism, questioning of assumptions, and even open-ended play, will result in decreased scientific progress rather than the reverse. When one is only ever encouraged to think within the box, it becomes ever harder even to conceive of thinking out of it, to distort a common saying.

There is therefore an inherent danger in the concept of ontological levels though it has a self-evident appeal. A loaf of bread has this identity at the level of human perception, beneath which it can be understood as the result of chemical processes binding certain molecules, beneath which it is, as is everything else, the product of universal physical forces and quantum mechanics. However, each of these levels is an interpretation. We can only know with absolute certainty that $\mathrm{X}$ is $\mathrm{X}$, not that $\mathrm{X}$ is the result of various factor-Xs. We recognize the factor-Xs in X, not the other way round. To avoid this lapse into a post-hoc propter-hoc fallacy, this argument will proceed by citing perceptual rather than ontological levels. This makes clear that we see rather than merely find constitutive elements and processes within substances and events.

Returning to the distinction between QPL and ICL above, one objection to this argument appeals to mathematics. Mathematics systematizes and 
generalizes regularities of pattern; at least, it is intended to. On this basis, the counter-argument runs, there are fundamental laws that operate at all ontological levels and thus ensure the necessary connections between them. This can be countered on three grounds. First, mathematics follows experience. Ultimately, as with all explanations, it is derived from empirical evidence at QPL. Secondly, mathematical formulae do not reveal their meanings without interpretation. Even fundamental concepts such as gravity, photon, or attraction cannot be directly mathematically derived. Thirdly, the more mathematics generalizes, the more it reduces, rather than increases, distinctions. (For example, Einstein's $e=m c^{2}$ leads us to realize we were wrong entirely to separate space and time, as Newton and Kant had done before.)

\section{Cultural dependence of interpretation and recognition}

Studies in the history and philosophy of science have long recognized that the recognitions of scientists are culturally dependent, if not determined. In any situation, both scientists and artists - indeed, any practitioner whatsoever can only respond to the situation via a selection of the cultural resources and explanatory theories available. For example, David Gooding's extensive work on the notebooks of Michael Faraday reveals how what is seen and recognized as experimental outcomes is dependent on assumptions held within the scientific community and on the measuring technology and is not merely the result of discovery in the literal sense. A more specific example is given by Harry Collins' discussion of cultural interpretations of data in the context of the search for gravitational waves (Collins 1998).

At times, this dependence on culturally available resources has resulted in what nowadays seem absurd outcomes. For example, Bill Bryson recounts the many experiments carried out in the 1700s to cure scurvy among sailors. The only such project to have immediate success was that led by a naval surgeon named James Lind, who found success by providing oranges and lemons (with vinegar to another group and garlic and mustard to a third, neither of which was successful). However, as no theory existed to explain why this might have had the desired effect, the outcomes were put down to chance and the experiment lay neglected (including by its originator) for several more years. Lind held to his theory that scurvy "was caused by incompletely indigested food building up toxins within the body," thereby not merely refusing to allow the data to challenge his hypothesis, but refusing to do so when he had set up the 
experiment explicitly to solve the riddle: an extreme example of experimentation driven by a will to confirm theory (Bryson 2010: 244). Without extant theories, we literally do not know what we are looking at. Interpretation requires interpretative frameworks.

\section{Analysis as analogy}

This implies that all analytical thinking apart from spotting exact repetition ( $\mathrm{X}=$ $\mathrm{X}$ ) is analogical (X reminds me of $\mathrm{Y}$ ). Even in the case of repetition, the experience is of being reminded of the first case. To look into something is always to be reminded of something else. This is how, for example, the scientist "sees" sub-atomic particles or the complex structure of atoms, molecules, and DNA double helixes in otherwise indeterminate observation data. We see what we are looking for except where the data preclude this, rather than the other way round. Vast research programs are funded with the aim of confirmation rather than refutation.

The arts operate rather differently. Here, the expectation is that the artist's looking into things will result in new insights. Art's function is to make us see things differently. In the arts, looking into things may open a can of worms, as the saying goes: that is, confront us with manifestations of our otherwise suppressed fears or, more happily, aspirations. In this sense, analysis can result in things seeming bigger on the inside than the outside: there is so much within something that the brute fact of its former status seems trivial.

C. S. Lewis uses this device in his Narnia stories for children, to relate to spiritual trials and quests. At the beginning of the series, in The Lion, the Witch and the Wardrobe, the children enter a world of cruel winter and despotism (winter without Christmas) through a dark wardrobe, while at the end, in The Last Battle, they ascend a hillside of fortifications, each proving to be larger than those on the slopes beneath them. ${ }^{5}$ In each case, what appeared to be the large quotidian world is transcended through spiritual engagement, first with evil (paradise lost, as a sort of induction into adolescence) and ultimately with salvation (paradise regained, as a sort of attainment of adult insight). There is no inferred microscopic constructional level here, however, as there is in scientific investigation; everything operates at the QPL, but more richly as investigation opens up analogies to produce new insights.

5 See: https://b2dbuntu.files.wordpress.com/2009/10/thechroniclesofnarnia.pdf, accessed January 27, 2016. 
In short, in science, at least in Kuhnian normal science, looking into things is generally an attempt to consolidate an explanation, supplementing it incrementally, while in the arts, and sometimes in qualitative social science, it is an attempt to "make the familiar strange" by seeing within things and finding the unexpected. Unexpected, and sometimes groundbreaking, results come in science when the data stubbornly refuse to endorse the explanation, but this is a rarity, and perhaps increasingly so, whereas in the arts, any look into things that does not make us see things somewhat differently will likely be rejected. Reinforcement of an existing explanation, and thus of predictability, is not generally regarded as aesthetically satisfying.

This may help explain the problems qualitative social scientists can have in terms of academic status and funding. There is less value attached to normal science in fields such as ethnography and narrative studies. This in turn may be because reinforcement of new explanations in the physical sciences more likely results in technological innovations, such as advances in medical science and practice, that are seen as worthier returns on investment than studies reinforcing explanations about aspects of human behavior that are not seen to be producing such innovations. Furthermore, normal science requires a more elaborate, expensive infrastructure than paradigm-breaking art. (Let it not be forgotten that much research into the arts is "scientific" in these terms, so may also require some complex infrastructure, though rarely if ever does arts research require a facility such as the large hadron collider at CERN near Geneva.)

The point of the present argument is by no means to downplay the value or importance of "hard science" by construing analytical processes as essentially analogical. Rather, it is to stress that all forms of human activity that involve looking into things, as opposed to regarding them merely as ready-to-hand (Heidegger 1962) involve seeing something and concluding "it looks like this." Much scientific research is a self-fulfilling prophecy, and implications and technological advances accrue as explanations (theories) are reinforced and refined. However, there is always a danger to be countered here. Rather, as a "learning outcomes" approach can diminish the learning experience for students by reducing the chances of unexpected outcomes, so programs of support for research can undermine radical scientific progress by valuing reinforcement over innovation and revaluation.

If this is not kept in mind, academic research can become an ever less innovative enterprise that demands increasing resource yet produces diminishing insights. Resource brings lobbying power, and the hard science community inevitably has this in much greater quantity than arts and humanities based practitioners or academics. However, it should be borne in 
mind that the arts, where new ways of seeing are almost de rigueur, have some case for comparative support. To acknowledge that seeing into things is to be reminded is not a confirmation of self-defeating relativism, and is certainly not anti-realist. It is rather an acknowledgment that theories depend on analysis for both confirmation and reformation on two levels: both for minor tweaking and radical reformulation. Analysis does not simply show us how things are in any explanation-neutral manner. We look into things to develop our explanations of the world, not to discover how the world really is in any absolute, culture-free sense.

\section{Analysis in the context of explanation- sensitivity}

In educational and scholarly practice generally, naïve scientific realism tends to be a default position: that is, procedure follows the assumption that by looking into something, one sees what is really and indisputably there. The procedure is one of simple discovery rather than interpretation. This is naïve on two fronts: first, in the philosophical sense of naïve scientific realism (that is, the assumption that what is observed is innocent of the observer but simply "is"); secondly, as the less experienced the researcher or learner, the more dependent he or she is on received, and not necessarily well understood, dominant explanatory frameworks - that is to say, the explanatory framework tends to be taken for granted.

Consider "fairness." There is no objective way of analyzing fairness, as the concept has different, though overlapping, definitions in different language games.

\section{Game 1: A fair test}

The teaching of young children often involves making them aware of the concept of a fair test. It can thus be a central plank in the induction of young people into scientific procedures. Though doubtless not usually explained to children in these terms, a fair test is one which tests what it claims to by controlling extraneous variables. If we wished to test the rainproofing qualities of two jackets and left one out in the rain while the other was in the house, we would not be undertaking a fair test. Often a fair test requires laboratory conditions so that all potentially intervening variables can be controlled. In the above case, for example, the result should be the outcome of simply the action of the independent variable (the pouring of the water) on the dependent 
variable (the level of water resistance of the jacket surface). All other intervening variables that might otherwise affect the outcome (such as temperature, the previous level of dampness of each jacket, wind strength, and so on) must be controlled and equalized or the experiment will not be valid. To construct a fair test, therefore, involves a conception of fairness that is quite different from the following.

\section{Game 2: A fair society}

From a very early age, people employ the concept of fairness to refer to some conception of justice, often distributive. Note that not only is the language game different in kind here, but also in openness. The meaning of a fair test in the above context is unequivocal, whereas what constitutes a fair society is a matter of fierce ongoing debate. Even if we were to agree with our students that, say, "A fair society is one in which everyone has a chance to succeed," the scope for interpretation of this is huge, requiring clarifications that can probably never be reached over issues including the nature of success and whether "a chance" refers to one only or to endless opportunities, regardless of desert or merit. There are further indirect implications relating to equally broad issues such as those of equality and the role of government. Language games clearly differ not only substantively but also procedurally.

\section{Game 3: Fair human coloring}

"Fair" here relates to coloring, but usually only in the context of human skin and hair. Thus, as in Game 1, the meaning of the concept within the game is relatively unambiguous, but, as in Game 2, there is scope for ambiguity and argument, though perhaps not to the same extent. One might debate, for example, the degree to which fairness is a social advantage or disadvantage, bearing in mind both racialist considerations and prejudices against redheads and the health issues around both too much sun exposure and Vitamin D deficiency.

\section{Game 4: Fair weather}

"Fair" here is frankly ambiguous. It can mean "settled" or the weather can "be set fair" for some activity or other. A fair day for sailing would require some breeze, whereas in other contexts calm might predominate. It seems to be little more than a vague term of approval of whether that does not intrude on desired activities. In contrast to Games 1 and 3, but in the spirit of Game 2, looking into what fair means here tends to problematize the univocality of the concept. There is an even vaguer use of "fair" in some informal contexts to indicate mild approval, as in the saying "fair enough." 
In each of these cases, we start with what is widely recognized as the spirit of analysis: looking more closely into something to see what we find. What is being challenged here is the idea that there is only one correct set of things that can and should be found when we do this. As often as possible, we should remind ourselves that there are several possible interpretations of the data, corresponding to existing theoretical models, while the data can be used, in Popperian spirit, to attempt to refute rather than confirm any of these such that the analysis contributes to theoretical development (Popper 2002).

The first task in the study of something is therefore not to break it into constituent parts but to be clear about its existential context, acknowledging that this, too, can be variously construed and is open to interpretation. For example, bread (as a comestible) is something associated with cereal farming, milling, and baking industries. It is knowledge of this that gives one the means to recognize the constituent parts of bread, not the rigor of analysis. If we fail in analysis, it is not so much because we cannot analyze as because we were not sure what we were looking at in the first place.

Furthermore, what we were looking at is a matter of intersubjective tradition, not internal quality nor the direct expression of reason. In this sense, as Kierkegaard pointed out, the subjective is always bigger than the objective (Minton 2000). However, interpretation is a matter of culture not of solipsism. There are no private languages, but there are no truths innocent of description. There are, however, shortcuts to apparent scientific progress. These shortcuts should be acknowledged as traps. Superficially, research that builds incrementally and unproblematically on the dominant vein of existing work offers good value for money. The high road of greater problematization may seem less appealing to research funders and curriculum planners (whose responsibility it is to train the scientists of the future), but avoiding it may in effect be cutting dead the chances of radical scientific advances.

\section{Conclusion}

The main educational implication of my argument is that all students should be aware of the explanation-sensitivity of analysis. This is congruent with the basic tenets of edusemiotics (Stables and Semetsky 2015), which is grounded in a rejection of Cartesian substance dualism with its associated tendency to separate off an objective, law-governed world from intersubjective, rulegoverned experience. The present argument also draws on Wittgenstein's later work (particularly Wittgenstein 1967) and particularly his concepts of "language 
game" and "form of life." Wittgenstein moved from his earlier pronouncement that "the world is everything that is the case" (Wittgenstein 2007, first published 1922: 1) to a more pluralist and pragmatist position whereby a truth can only hold within the context of an explanation (as opposed to vice versa). The upshot of this is that a concept that can be taken as innocent and univocal in terms of meaning will look quite different when investigated in the contexts of different language games.

\section{References}

Bryson, Bill. 2010. At Home: A Short History of Private Life. London: Transworld.

Collins, Harold Maurice. 1998. The Meaning of Data: Open and Closed Evidential Cultures in the Search for Gravitational Waves. American Journal of Sociology 104/2, 293-338.

Gooding, David. 1990. Experiment and the Making of Meaning. New York: Springer.

Hanlon, Michael. 2014. The Golden Quarter. Aeon Dec 3, 2014. https://aeon.co/essays/hasprogress-in-science-and-technology-come-to-a-halt (accessed January 26, 2016).

Hartmann, Nicolai. 1935. Ontologie (4 volumes) I: Zur Grundlegung der Ontologie. Berlin/Leipzig: De Gruyter.

Heidegger, Martin. 1962. John Macquarrie and Edward Robinson (trans.). Being and Time. New York: Macmillan.

Minton, Stephen James. 2000. Kierkegaard and Truth as Subjectivity. Practical Philosophy 3(2), July 2000. http://www.society-for-philosophy-in-practice.org/journal/pdf/3-2\%2024\%20 Minton\%20-\%20Kierkegaard.pdf (accessed January 27, 2016).

Popper, Karl. 2002. The Logic of Scientific Discovery. London: Routledge.

Rorschach, Hermann. 1927. Rorschach Test-Psychodiagnostic Plates. Cambridge, MA: Hogrefe.

Stables, Andrew \& Inna Semetsky. 2015. Edusemiotics: Semiotic Philosophy as Educational Foundation. London: Routledge.

Whitehead, Alfred North. 1929. Process and Reality. An Essay in Cosmology. New York: Macmillan.

Wittgenstein, Ludwig. 1967. Philosophical Investigations. Oxford: Blackwell.

Wittgenstein, Ludwig. 2007. Charles Kay Ogden (trans.). Tractatus Logico-Philosophicus. New York: Cosimo.

\section{Bionote}

\section{Andrew Stables}

Andrew Stables (b. 1956) is Professor of Education and Philosophy and Deputy Director for Research in the School of Education, University of Roehampton, London. He has developed a semiotic approach to educational theory, as outlined in Living and Learning as Semiotic Engagement (2005), Be(com)ing Human: Semiosis and the Myth of Reason (2012), and (with 
Inna Semetsky) Edusemiotics: Semiotic Philosophy as Educational Foundation (2015), which won the Philosophy of Education Society of Australasia New Book Award in 2015. 